\title{
Clinical Characteristics of Transient Ischemic Attack Patients with Atrial Fibrillation: Analyses of a Multicenter Retrospective Study
}

\author{
Yuka Hama $^{\mathrm{a}}$ Toshiyuki Uehara $^{\mathrm{a}}$ Tomoyuki Ohara $^{\mathrm{a}}$ Kazumi Kimura $^{\mathrm{c}}$

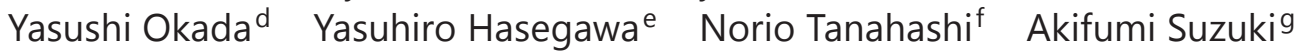 \\ Shigeharu Takagi ${ }^{\text {h }}$ Jyoji Nakagawara ${ }^{i}$ Kazumasa Arii ${ }^{j}$ Shinji Nagahiro' \\ Kuniaki Ogasawaram ${ }^{m}$ Takehiko Nagaok $^{k}$ Shinichiro Uchiyamak \\ Masayasu Matsumoton $^{n}$ Koji Iihara ${ }^{b}$ Kazunori Toyoda ${ }^{a}$ Kazuo Minematsu ${ }^{a}$ \\ Departments of a Cerebrovascular Medicine and beurosurgery, National Cerebral and \\ Cardiovascular Center, Suita, ' Department of Stroke Medicine, Kawasaki Medical School, \\ Kurashiki, dDepartment of Cerebrovascular Medicine and Neurology, Clinical Research \\ Institute, National Hospital Organization Kyushu Medical Center, Fukuoka, e Department \\ of Neurology, Nagoya Daini Red Cross Hospital, Nagoya, ${ }^{f}$ Department of Neurology and \\ Cerebrovascular Medicine, Saitama Medical University, Saitama International Medical Center, \\ Hidaka, ${ }^{9}$ Department of Stroke Science, Research Institute for Brain and Blood Vessels Akita, \\ Akita, h Department of Neurology, Tokai University, Isehara, 'Department of Neurosurgery, \\ Nakamura Memorial Hospital, Sapporo, jDepartment of Neurology, Ebara Hospital, and \\ kDepartment of Neurology, Tokyo Women's Medical University, Tokyo, 'Department of \\ Neurosurgery, Tokushima University, Tokushima, m Department of Neurosurgery, Iwate Medical \\ University, Morioka, and ${ }^{\mathrm{n}}$ Department of Clinical Neuroscience and Therapeutics, Hiroshima \\ University, Hiroshima, Japan
}

Key Words

Transient ischemic attack · Atrial fibrillation · Diffusion-weighted imaging

\section{Abstract}

Background: Atrial fibrillation (AF) is an important risk factor for transient ischemic attack (TIA). However, little is known about the characteristics of TIA patients with AF. This study investigated the characteristics of such patients, using data from a retrospective, observational, multicenter study. Methods: TIA patients admitted to 13 stroke centers in Japan within 7 days of onset between January 2008 and December 2009 were included. The present analyses compared baseline characteristics, clinical symptoms, findings from diffusion-weighted imaging (DWI), and clinical outcomes between patients with and without AF (AF and non-AF groups). Results: A total of 464 patients (292 men; mean age $68.5 \pm 13.2$ years) were registered. Of these, 79 patients (17\%) had AF. Patients in the AF group were older (73.9 \pm 9.1 vs. $67.4 \pm 13.6$ years, $p<0.001)$ and more likely to show disturbance of consciousness $(13$ vs. $6 \%$, 
$p=0.046)$ and aphasia ( 9 vs. $3 \%, p=0.007$ ) than patients in the non-AF group. Although no difference in the overall DWI-positive rate was seen between the groups ( 28 vs. $20 \%, p=$ 0.102 ), a single lesion ( 23 vs. $10 \%, p<0.001$ ), a lesion $\geq 15 \mathrm{~mm}(11$ vs. $4 \%, p=0.006)$, and a single lesion $\geq 15 \mathrm{~mm}$ (11 vs. $2 \%, \mathrm{p}<0.001)$ on DWI were more frequent in the AF group. Multivariate logistic regression analysis identified increased age [odds ratio (OR) 1.04; $95 \%$ confidence interval (CI) 1.02-1.07] and DWI single lesion $\geq 15 \mathrm{~mm}$ (OR 5.67; 95\% CI 1.92-16.7) as independently associated with the presence of AF. Conclusions: In this study, 17\% of our TIA patients had AF. We found an association between the acute ischemic lesion pattern on DWI of a single lesion $\geq 15 \mathrm{~mm}$ and AF in TIA patients. These results might lead to a better diagnosis of TIA patients with AF.

(c) 2015 S. Karger AG, Basel

\section{Introduction}

Transient ischemic attack (TIA) is a medical emergency associated with a high risk of early subsequent stroke. Around 10-15\% of TIA patients develop stroke within 90 days, with half of these strokes occurring within the first $48 \mathrm{~h}$ [1-4]. Identifying mechanisms of TIA and initiating proper treatment as soon as possible are thus important in reducing the risk of stroke after TIA. Atrial fibrillation (AF) represents an important risk factor for TIA, but little is known about the characteristics of TIA patients with AF. The purpose of this study was to investigate the characteristics of such patients using data from a multicenter, retrospective study.

\section{Methods}

The methods of this study have been described in detail elsewhere [5-7]. In brief, this retrospective, observational, multicenter study enrolled TIA patients admitted to 13 stroke centers in Japan within 7 days of symptom onset between January 2008 and December 2009. Patients were diagnosed as having TIA if neurological symptoms and signs lasted less than $24 \mathrm{~h}$, regardless of brain imaging findings.

We recorded the following information on each patient: sex, age, body mass index, risk factors, past history of stroke, premorbid modified Rankin Scale (mRS), neurological symptoms, and National Institutes of Health Stroke Scale score on admission. We also calculated individual $\mathrm{ABCD}^{2}$ scores. Diffusion-weighted imaging (DWI) was also performed with a 1.5-tesla system to evaluate whether acute ischemic lesions were present on admission. Acute ischemic lesions were defined as areas of signal hyperintensity on DWI. Neuroradiologists or physicians specialized in stroke evaluated the patterns of acute ischemic lesions on DWI, including their number (single or multiple) and size (largest diameter $\geq 15$ or $<15 \mathrm{~mm}$ ). Duration of hospitalization, events including TIA recurrence, ischemic stroke, or systemic embolism during hospitalization, and $\mathrm{mRS}$ at day 30 were used as clinical outcomes. Each local ethics committee approved the retrospective collection and submission of patients' clinical data to the study office at the National Cerebral and Cardiovascular Center.

TIA patients were divided into two groups: patients with AF (AF group) and patients without AF (non-AF group). AF was considered present if it was previously known or newly documented on electrocardiography during hospitalization. We compared baseline characteristics, clinical symptoms, DWI findings, and clinical outcome between groups.

All statistical analyses were performed using JMP statistical software (version 9.0.2; SAS Institute, Cary, N.C., USA). Results are expressed as mean \pm standard deviation (SD) or median (25th, 75th centile) and as the number of patients and percentage for categorical variables as appropriate. Baseline characteristics, symptoms, DWI lesion patterns, and clinical outcomes were compared between the groups using the $\chi^{2}$ test, Student's t test, and the Wilcoxon test as appropriate. Statistical significance was set at the level of $p<0.05$. Multivariate analyses were performed to identify predictors of the presence of AF. Sex, age, and variables showing values of $\mathrm{p}<0.05$ in univariate analysis were entered into the multivariate analyses. 
Table 1. Baseline characteristics of the AF and non-AF groups

\begin{tabular}{lcclr}
\hline & $\begin{array}{l}\text { All patients } \\
(\mathrm{n}=464)\end{array}$ & $\begin{array}{l}\text { Patients with AF } \\
(\mathrm{n}=79)\end{array}$ & $\begin{array}{l}\text { Patients without AF } \\
(\mathrm{n}=385)\end{array}$ & p value \\
\hline Male sex & $292(63)$ & $47(59)$ & $245(64)$ & 0.487 \\
Age, years & $68.5 \pm 13.2$ & $73.9 \pm 9.1$ & $67.4 \pm 13.6$ & $<0.001$ \\
BMI & $23.0 \pm 3.6$ & $23.1 \pm 3.4$ & $23.0 \pm 3.6$ & 0.790 \\
Risk factors & & & & \\
$\quad$ Hypertension & $319(69)$ & $51(65)$ & $268(70)$ & 0.377 \\
$\quad$ Diabetes mellitus & $94(20)$ & $14(18)$ & $80(21)$ & 0.538 \\
$\quad$ Dyslipidemia & $181(39)$ & $28(35)$ & $153(40)$ & 0.476 \\
$\quad$ Current smoking & $121(26)$ & $12(15)$ & $109(28)$ & 0.016 \\
$\quad$ Habitual drinker & $119(26)$ & $16(20)$ & $103(27)$ & 0.228 \\
Past history of stroke & $108(23)$ & $19(24)$ & $89(23)$ & 0.858 \\
$\quad$ Overall & $101(22)$ & $18(23)$ & $83(22)$ & 0.810 \\
$\quad$ Ischemic stroke & $11(2)$ & $2(3)$ & $9(2)$ & 1.000 \\
$\quad$ Intracerebral hemorrhage & $1(0)$ & $0(0)$ & $1(0)$ & 1.000 \\
$\quad$ Subarachnoid hemorrhage & $0(0-0)$ & $0(0-0)$ & $0(0-0)$ & 0.553 \\
Premorbid mRS & & & &
\end{tabular}

Values are mean $\pm \mathrm{SD}, \mathrm{n}(\%)$, or median (interquartile range). BMI = Body mass index.

Table 2. Clinical symptoms and $\mathrm{ABCD}^{2}$ score in the $\mathrm{AF}$ and non-AF groups

\begin{tabular}{lcccc}
\hline & $\begin{array}{c}\text { All patients } \\
(\mathrm{n}=464)\end{array}$ & $\begin{array}{l}\text { Patients with AF } \\
(\mathrm{n}=79)\end{array}$ & $\begin{array}{l}\text { Patients without AF } \\
(\mathrm{n}=385)\end{array}$ & p value \\
\hline $\begin{array}{l}\text { Clinical symptoms } \\
\text { Disturbance of consciousness }\end{array}$ & $34(7)$ & $10(13)$ & $24(6)$ & \\
$\quad$ Gaze disturbance & $6(1)$ & $3(4)$ & $3(1)$ & 0.046 \\
Visual field defect & $6(1)$ & $1(1)$ & $5(1)$ & 0.065 \\
Facial palsy & $33(7)$ & $5(6)$ & $28(7)$ & 0.000 \\
Hemiparesis & $100(22)$ & $13(16)$ & $87(23)$ & 0.227 \\
Ataxia & $13(3)$ & $1(1)$ & $12(3)$ & 0.706 \\
Dysesthesia & $68(15)$ & $6(8)$ & $62(16)$ & 0.051 \\
Aphasia & $17(4)$ & $7(9)$ & $10(3)$ & 0.007 \\
Dysarthria & $60(13)$ & $7(9)$ & $53(14)$ & 0.237 \\
$\quad$ Tactile extinction & $7(2)$ & $2(3)$ & $5(1)$ & 0.340 \\
NIHSS score on admission & $0(0-1)$ & $0(0-2)$ & $0(0-1)$ & 0.969 \\
Single TIA & $364(78)$ & $64(81)$ & $300(78)$ & 0.543 \\
ABCD 2 score & $5(4-6)$ & $5(4-5)$ & $5(4-6)$ & 0.491 \\
\hline
\end{tabular}

Values are n (\%) or median (interquartile range). NIHSS = National Institutes of Health Stroke Scale.

\section{Results}

Participants comprised 464 patients (292 men; age $68.5 \pm 13.2$ years). Of these, 79 patients $(17 \%)$ had AF. The AF group was older $(73.9 \pm 9.1$ vs. $67.4 \pm 13.6$ years, $p<0.001)$ and showed a lower frequency of current smokers (15 vs. $28 \%, \mathrm{p}=0.016)$ than the non-AF group (table 1). Table 2 presents clinical symptoms and $\mathrm{ABCD}^{2}$ scores of the $\mathrm{AF}$ and non-AF groups. Disturbance of consciousness ( $13 \mathrm{vs.} 6 \%, \mathrm{p}=0.046$ ) and aphasia ( 9 vs. $3 \%, \mathrm{p}=0.007$ ) were significantly more frequent in the AF group than in the non-AF group. Of the 464 patients, 
Hama et al.: Clinical Characteristics of Transient Ischemic Attack Patients with Atrial Fibrillation: Analyses of a Multicenter Retrospective Study

Table 3. DWI findings of the AF and non-AF groups

\begin{tabular}{llllr}
\hline & $\begin{array}{l}\text { All patients } \\
(\mathrm{n}=458)\end{array}$ & $\begin{array}{l}\text { Patients with AF } \\
(\mathrm{n}=75)\end{array}$ & $\begin{array}{l}\text { Patients without AF } \\
(\mathrm{n}=383)\end{array}$ & $\mathrm{p}$ value \\
\hline DWI findings & & & $75(20)$ & 0.102 \\
Overall & $96(21)$ & $21(28)$ & $38(10)$ & $<0.001$ \\
Single lesion & $56(12)$ & $18(24)$ & $16(4)$ & 0.006 \\
Lesion $\geq 15 \mathrm{~mm}$ & $25(5)$ & $9(12)$ & $9(2)$ & $<0.001$ \\
Single lesion $\geq 15 \mathrm{~mm}$ & $17(4)$ & $8(11)$ & \\
\hline
\end{tabular}

Values are $\mathrm{n}(\%)$

Table 4. Clinical outcomes of the AF and non-AF groups

\begin{tabular}{lllll}
\hline & $\begin{array}{l}\text { All patients } \\
(\mathrm{n}=464)\end{array}$ & $\begin{array}{l}\text { Patients with AF } \\
(\mathrm{n}=79)\end{array}$ & $\begin{array}{l}\text { Patients without AF } \\
(\mathrm{n}=385)\end{array}$ & p values \\
\hline $\begin{array}{l}\text { Duration of hospitalization, days } \\
\text { Events during hospitalization }\end{array}$ & $11(8-17)$ & $13(9-18)$ & $11(7-17)$ & 0.047 \\
$\quad$ & $27(6)$ & $3(4)$ & $24(6)$ & 0.597 \\
$\quad \begin{array}{l}\text { TIA recurrence } \\
\text { Systemic stroke }\end{array}$ & $8(2)$ & $2(3)$ & $6(2)$ & 0.629 \\
mRS at 30 days & $4(1)$ & $2(3)$ & $2(1)$ & 0.136 \\
\end{tabular}

Values are $\mathrm{n}(\%)$ or median (interquartile range).

$458(99 \%)$ underwent MRI of the head. Acute ischemic lesions were detected in 96 patients (21\%). No difference in the overall DWI lesion rate was seen between the groups (28 vs. 20\%, $\mathrm{p}=0.102$ ). Compared to patients in the non-AF group, patients in the AF group were more likely to show a single lesion ( 24 vs. $10 \%, \mathrm{p}<0.001)$, a lesion $\geq 15 \mathrm{~mm}(12 \mathrm{vs} .4 \%, \mathrm{p}=0.006)$, or a single lesion $\geq 15 \mathrm{~mm}$ (11 vs. $2 \%$, p < 0.001 ) on DWI (table 3). For clinical outcomes, the median duration of hospitalization was longer in the AF group than in the non-AF group [median (interquartile range): 13 (9-18) vs. 11 (7-17), $p=0.047$ ]. No significant differences in the incidence of TIA recurrence ( 4 vs. 6\%), ischemic stroke (3 vs. 2\%), or systemic embolism (3 vs. 1\%) during hospitalization, and mRS at day 30 were evident between the groups (table 4). Multivariate logistic regression analysis identified increased age [odds ratio (OR) 1.04; 95\% confidence interval (CI) 1.02-1.07] and DWI single lesion (OR 2.32; 95\% CI 1.094.78 ) as independently associated with the presence of AF. When using data for the combination of DWI single lesion and lesion $\geq 15 \mathrm{~mm}$ in model 2, increased age (OR 1.04; 95\% CI 1.02-1.07) and DWI single lesion $\geq 15 \mathrm{~mm}$ (OR 5.67; 95\% CI 1.92-16.7) were independently associated with the presence of AF (table 5).

\section{Discussion}

In this study, $17 \%$ of TIA patients had AF, and advanced age was associated with the presence of AF. According to the Hisayama study, $16 \%$ of TIA patients in a Japanese community had AF or valvular heart disease [8]. In the Japan Multicenter Stroke Investigators' Collaboration (J-MUSIC) registry of 1,084 TIA patients, the frequency of AF was $17 \%$, and TIA patients 

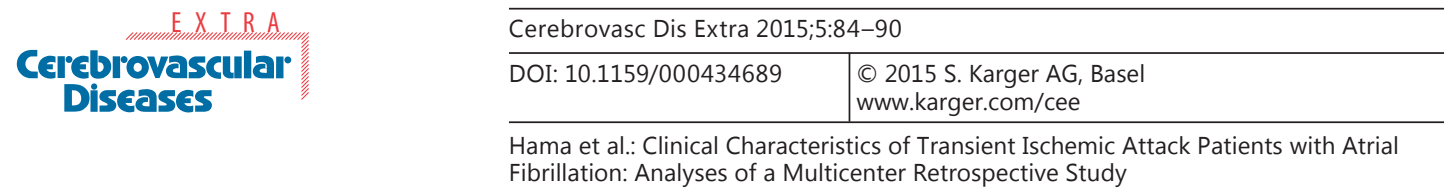

Table 5. Multivariate logistic regression analysis for the factors associated with presence of AF

\begin{tabular}{|c|c|c|c|c|c|c|}
\hline & \multicolumn{3}{|c|}{ Multivariate-adjusted model 1} & \multicolumn{3}{|c|}{ Multivariate-adjusted model 2} \\
\hline & OR & $95 \% \mathrm{CI}$ & $\mathrm{p}$ value & OR & $95 \% \mathrm{CI}$ & $\mathrm{p}$ value \\
\hline Male sex & 0.93 & $0.55-1.60$ & 0.80 & 0.93 & $0.55-1.60$ & 0.79 \\
\hline Age & 1.04 & $1.02-1.07$ & $<0.001$ & 1.04 & $1.02-1.07$ & $<0.001$ \\
\hline Current smoking & 0.59 & $0.28-1.15$ & 0.13 & 0.56 & $0.26-1.09$ & 0.09 \\
\hline \multicolumn{7}{|l|}{ Clinical symptoms } \\
\hline Consciousness disturbance & 1.56 & $0.64-3.57$ & 0.32 & 1.45 & $0.59-3.32$ & 0.40 \\
\hline Aphasia & 2.32 & $0.75-6.81$ & 0.14 & 2.38 & $0.77-6.92$ & 0.13 \\
\hline DWI single lesion & 2.32 & $1.09-4.78$ & 0.03 & & & \\
\hline DWI lesion $\geq 15 \mathrm{~mm}$ & 2.13 & $0.74-5.84$ & 0.16 & & & \\
\hline DWI single lesion $\geq 15 \mathrm{~mm}$ & & & & 5.67 & $1.92-16.7$ & 0.002 \\
\hline
\end{tabular}

Model 1: adjusted for sex, age, and factors with $\mathrm{p}<0.1$ in univariate analysis. Model 2: integration of DWI single lesion $\geq 15 \mathrm{~mm}$ in addition to factors from model 1 .

with AF were likely to be older compared to those without AF [9]. Our results were consistent with those of previous studies in Japan. On the other hand, a previous study of 1,429 TIA patients registered in Germany reported AF in $11 \%$ of patients [10]. Another study in northern California demonstrated that $9 \%$ of 1,707 TIA patients had AF [11]. These results indicate that the frequency of AF in patients with TIA is higher in Japanese populations than in European or American populations. This difference may be explained in part by differences in patient background, extent of diagnostic workup, and ethnicity.

This study determined the association between acute ischemic lesion patterns on DWI and AF in TIA patients. In the abovementioned J-MUSIC study, multiple logistic regression analysis revealed disturbance of consciousness and speech disturbance as factors independently associated with AF in TIA patients. This may be because cardioembolic TIA tends to involve the cortical region. The J-MUSIC study mentioned that these results may support the hypothesis that TIA patients with AF have larger emboli originating from the left atrium than patients without $\mathrm{AF}$ and that ischemic lesions are also larger in TIA patients with AF than in those without $[8,9]$. We actually found that a single lesion $\geq 15 \mathrm{~mm}$ in size was associated with the presence of AF. Similar to our results, Purroy et al. [12] showed that a single cortical lesion was associated with cardioembolism in a study of 254 TIA patients.

In this study, patients in the AF group showed a longer duration of hospitalization than those in the non-AF group. This may be attributable to patients with AF needing a number of days for adjustment of warfarin dosages. No significant differences in the frequency of ischemic stroke or recurrent TIA during hospitalization were identified between the groups. In the same cohort, DWI-positive lesions, hypertension, and hemiparesis were reported as independent predictors of ischemic stroke or recurrent TIA during acute hospitalization [7].

Some limitations must be considered when interpreting the study results. First, a selection bias was present in this study, since only TIA patients admitted to stroke centers were enrolled. In addition, decisions regarding hospitalization and management of TIA patients were made by the individual attending physicians. Second, this study utilized a retrospective design, and data were missing for some baseline characteristics. Third, we did not have additional monitoring data on patients in whom AF was not detected before or during hospitalization. Holter monitors after hospitalization detect about $5 \%$ of cryptogenic stroke patients as having $\mathrm{AF}$, and 30-day monitors up to $20 \%$ [13]. Fourth, there are no data regarding events within 30 or 90 days. Given the potential continuous risk of AF, this represents a limitation in 
this study. Finally, an adequate analysis of clinical outcome was difficult due to the small number of events encountered during hospitalization.

In conclusion, $17 \%$ of our TIA patients showed AF. Increased age and a single lesion $\geq 15$ $\mathrm{mm}$ on DWI were associated with the presence of AF. The present results might lead to a better diagnosis of TIA patients with AF.

\section{Appendix}

\section{Chief Investigator}

K. Minematsu, National Cerebral and Cardiovascular Center.

\section{Investigators and Institutions}

Y. Hama, T. Uehara, T. Ohara, R. Suzuki, J. Fujinami, T. Miyagi, K. Tanaka, H. Matsushima, R. Shimomura, T. Matsushige, K. Iihara, and K. Minematsu, National Cerebral and Cardiovascular Center; T. Iwanaga, J. Uemura, and K. Kimura, Kawasaki Medical School; M. Mori, T. Uwatoko, S. Yoshimura, and Y. Okada, National Hospital Organization Kyushu Medical Center; K. Yasui and Y. Hasegawa, Nagoya Daini Red Cross Hospital; N. Tanahashi, Saitama Medical University; T. Nakase, S. Yoshioka, and A. Suzuki, Research Institute for Brain and Blood Vessels Akita; S. Takagi, Tokai University Tokyo Hospital; K. Ueyama and J. Nakagawara, Nakamura Memorial Hospital; K. Arii and T. Nagao, Ebara Hospital; J. Satomi and S. Nagahiro, Tokushima University; K. Ogasawara, Iwate Medical University; S. Mizuno, T. Hoshino, and S. Uchiyama, Tokyo Women's Medical University; N. Hosomi, T. Ohtsuki, and M. Matsumoto, Hiroshima University.

\section{Acknowledgement}

This study was supported in part by Grants-in-Aid (H21-Junkanki-Ippan-017 and H24-Junkanki-Ippan-011) from the Ministry of Health, Labor and Welfare of Japan (MHLWJapan).

\section{Disclosure Statement}

The authors have no conflicts of interest to disclose.

\section{References}

1 Easton JD, Saver JL, Albers GW, Alberts MJ, Chaturvedi S, Feldmann E, Hatsukami TS, Higashida RT, Johnston SC, Kidwell CS, Lutsep HL, Miller E, Sacco RL; American Heart Association; American Stroke Association Stroke Council; Council on Cardiovascular Surgery and Anesthesia; Council on Cardiovascular Radiology and Intervention; Council on Cardiovascular Nursing; Interdisciplinary Council on Peripheral Vascular Disease: Definition and evaluation of transient ischemic attack: a scientific statement for healthcare professionals from the American Heart Association/American Stroke Association Stroke Council; Council on Cardiovascular Surgery and Anesthesia; Council on Cardiovascular Radiology and Intervention; Council on Cardiovascular Nursing; and the Interdisciplinary Council on Peripheral Vascular Disease. The American Academy of Neurology affirms the value of this statement as an educational tool for neurologists. Stroke 2009;40:2276-2293.

2 Giles MF, Rothwell PM: Risk of stroke early after transient ischemic attack: a systematic review and metaanalysis. Lancet Neurol 2007;6:1063-1072.

3 Wu CM, McLaughlin K, Lorenzetti DL, Hill MD, Manns BJ, Ghali WA: Early risk of stroke after transient ischemic attack: a systematic review and meta-analysis. Arch Intern Med 2007;167:2417-2422. 
Hama et al.: Clinical Characteristics of Transient Ischemic Attack Patients with Atria Fibrillation: Analyses of a Multicenter Retrospective Study

4 Redgrave JN, Coutts SB, Schulz UG, Briley D, Rothwell PM: Systematic review of associations between the presence of acute ischemic lesions on diffusion-weighted imaging and clinical predictors of early stroke risk after transient ischemic attack. Stroke 2007;38:1482-1488.

5 Miyagi T, Uehara T, Kimura K, Okada Y, Hasegawa Y, Tanahashi N, Suzuki A, Takagi S, Nakagawara J, Arii K, Nagahiro S, Ogasawara K, Nagao T, Uchiyama S, Matsumoto M, Iihara K, Toyoda K, Minematsu K: Examination timing and lesion patterns in diffusion-weighted magnetic resonance imaging of patients with classically defined transient ischemic attack. J Stroke Cerebrovasc Dis 2013;22:e310-e316.

-6 Uehara T, Kimura K, Okada Y, Hasegawa Y, Tanahashi N, Suzuki A, Takagi S, Nakagawara J, Arii K, Nagahiro S, Ogasawara K, Nagao T, Uchiyama S, Matsumoto M, Iihara K, Minematsu K: Factors associated with onset-todoor time in patients with transient ischemic attack admitted to stroke centers. Stroke 2014;45:611-613.

7 Fujinami J, Uehara T, Kimura K, Okada Y, Hasegawa Y, Tanahashi N, Suzuki A, Takagi S, Nakagawara J, Arii K, Nagahiro S, Ogasawara K, Nagao T, Uchiyama S, Matsumoto M, Iihara K, Minematsu K: Incidence and predictors of ischemic stroke events during hospitalization in patients with transient ischemic attack. Cerebrovasc Dis 2014;37:330-335.

-8 Ueda K, Kiyohara Y, Hasuo Y, Yanai T, Kawano H, Wada J, Kato I, Kajiwara E, Omae T, Fujishima M: Transient cerebral ischemic attacks in a Japanese community, Hisayama, Japan. Stroke 1987;18:844-848.

-9 Inoue T, Kimura K, Minematsu K, Yamaguchi T; Japan Multicenter Stroke Investigators' Collaboration (J-MUSIC): Clinical features of transient ischemic attack associated with atrial fibrillation: analysis of 1,084 TIA patients. J Stroke Cerebrovasc Dis 2004;13:155-159.

10 Weimar C, Kraywinkel K, Rödl J, Hippe A, Harms L, Kloth A, Diener HC; German Stroke Data Bank Collaborators: Etiology, duration, and prognosis of transient ischemic attacks: an analysis from the German Stroke Data Bank. Arch Neurol 2002;59:1584-1588.

11 Johnston SC, Gress DR, Browner WS, Sidney S: Short-term prognosis after emergency department diagnosis of TIA. JAMA 2000;284:2901-2906.

-12 Purroy F, Begué R, Gil MI, Quílez A, Sanahuja J, Brieva L, Piñol-Ripoll G: Patterns of diffusion-weighted magnetic resonance imaging associated with etiology improve the accuracy of prognosis after transient ischemic attack. Eur J Neurol 2011;18:121-128.

13 Gladstone DJ, Spring M, Dorian P, Panzov V, Thorpe KE, Hall J, Vaid H, O’Donnell M, Laupacis A, Côté R, Sharma M, Blakely JA, Shuaib A, Hachinski V, Coutts SB, Sahlas DJ, Teal P, Yip S, Spence JD, Buck B, Verreault S, Casaubon LK, Penn A, Selchen D, Jin A, Howse D, Mehdiratta M, Boyle K, Aviv R, Kapral MK, Mamdani M; EMBRACE Investigators and Coordinators: Atrial fibrillation in patients with cryptogenic stroke. N Engl J Med 2014;370: 2467-2477. 